\title{
ÁNGEL CRESPO POETA DI FRONTE A DANTE
}

\author{
CATERINA ISOLDI ${ }^{1}$
}

Universidad de Pisa

\section{Resumen}

La larga intimidad con la poesía dantesca que la obra de traducción de la Comedia supuso para el poeta Ángel Crespo llega a marcar de manera muy profunda la obra poética del traductor. En efecto Dante aparece por una parte como personaje en la poesía crespiana, y al mismo tiempo la frecuentación de la obra dantesca parece impulsar una significativa profundización de las proposiciones artísticas del traductor. En el trabajo que se presenta aquí se investigan las huellas del poeta florentino en la memoria poética de Ángel Crespo.

Palabras clave: Dante, Crespo, poesía, osmosis, memoria, traductor

\begin{abstract}
The long work of translation of the Divine Comedy leads the spanish poet Ángel Crespo to such an intimacy with the poetry of Dante Alighieri that his own work cannot avoid being marked by this experience. Dante, who already appears as a character in Crespo's poetry before the translation, becomes from then on the promoter of a progressive growth of his translator's poetic ideals. This study investigates Dante's influence in the poetic memory of his translator.
\end{abstract}

Key Words: Dante, Crespo, poetry, influence, memory, translator

\section{Dante personaggio della poesia crespiana: "onore e lume"}

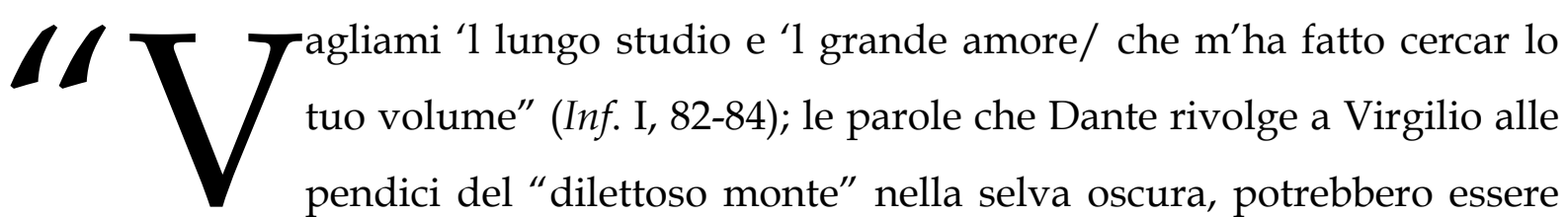
messe in bocca ad Ángel Crespo e rivolte a Dante. Come Virgilio nella Commedia,

\footnotetext{
1 Profesora de la Universidad de Pisa. Correo-e: caterina.isoldi@istruzione.it. Recibido: 06-02-2009; segunda versión: 13-04-2009.
} 
Dante è, infatti, per Crespo, “figura que ilumina a los seguidores del arte poético el camino de la sabiduría"2 . L'opera di Ángel Crespo resta segnata, infatti, in maniera indelebile dalla lunga osmosi con il testo dantesco, che l'opera di traduzione della Commedia significò per il poeta.

Nella poesia crespiana la figura di Dante come guida dell'anima alla trascendenza, appare legata all'esperienza del fuoco catartico decisiva per conoscere la verità di sé stessi, e per ricevere l'illuminazione e il riverbero di quella verità. Il significato del personaggio di Dante, emerge chiaramente nella poesia Indicios del temor $^{3}$ che rivive l'impasse del poeta davanti alla barriera di fuoco del canto XXVII del Purgatorio. Il testo è tutto percorso (percosso) da un brivido di fonemi vibranti: la coppia di vocale e vibrante presente nel titolo nella parola "temor" si ripete in ogni verso, a rappresentare il tremore per il passo decisivo, il timore di "dar un paso más" ${ }^{4}$. Il passo da compiere è tanto più decisivo, in quanto si tratta di quello che fa la differenza tra la realizzazione della propria persona, e la non-realtà. Si legge, infatti, in un testo crespiano degli anni cinquanta dal titolo La huida": "todo lo que he podido realizar/ y me faltó, no más, un paso"; la realtà in potenza verrebbe dunque realizzata in quel passo, e solo in quel passo ("no más"), che rappresenta l'espressione decisiva dell'umanità del poeta.

\footnotetext{
2 Ángel Crespo, Dante y su obra, El Acantilado, Barcelona 1999, p. 120.

${ }^{3}$ Da Ocupación del fuego (1986-1989), in Ángel Crespo, Poesía, eds. Pilar Gómez Bedate y Antonio Piedra, Fundación Jorge Guillén, Valladolid 1996, tomo 3, p. 225 (in seguito Poesía 1996).

4 “Un paso más y me encontraré con un dios. Sería demasiado pequeño. Voy rodeando para no retroceder, para no encontrarle" (Ángel Crespo, Aforismos). Condannato dalla propria inadeguatezza ("sería pequeño") ad un movimento circolare, improgressivo ed atemporale (uso dei verbi di modo infinito "voy rodeando", "no retroceder", "no encontrarlo"), il poeta tremante sembra ritrovare la sua energia nella sequela del paradigma dantesco.

${ }^{5}$ Da En medio del camino (1949-1970), in Poesía 1996, tomo 1, p. 127.
} 
Cito Indicios del temor:

\author{
¿El aire no ha de arder \\ cuando sus cuerdas vibran \\ para evocar - espejo - al fuego? \\ ¿Y la garganta no han de sofocar \\ sus presentidas llamas? \\ Recuerdo a Dante, que al final entró \\ en el fuego de la última cornisa \\ de la montaña, y excesivo \\ le pareció para fundir cristal \\ aquel ardor sobrado.
}

\author{
Mas ¿qué exceso \\ será éste, que así funde \\ - más sutil que cristal, más fugitiva \\ que transparente es el cristal - la voz? \\ De Dante, ni un cabello \\ quemó, ni la orla de su túnica: \\ ni el pespunte de la orla de su túnica \\ ardió. \\ Mas ¿siempre acaso el fuego \\ muestra así su verdad, \\ el ser de su verdad de claridad, \\ a quien le huía y se le entrega luego?
}

L'aria, il respiro vitale, si trasforma in uno strumento musicale, come se lo spasimo poietico producesse una vibrazione sonora ("sus cuerdas vibran") che, infiammando l'atmosfera ("arder"), fosse capace di suscitare, o di reinventare, il fuoco, luce e calore, strumento di rivelazione e condizione di verità, che nella metamorfosi della consumazione restituisce le cose alla segreta ed essenziale nudità dello spirito. L'atmosfera ("el aire"), condizione necessaria alla vita sulla terra, è concepita come spasimo di parola (di significato), specchio ed evocazione, vibrante per il riverbero del fuoco che riflette. L'ardore estremo della purificazione ("exceso"), può fondere la voce ("¿qué exceso/ será este, que así funde/ - más sutil que cristal, más fugitiva/ que transparente es el cristal - la voz?") perché possa amalgamarsi, fondersi con le cose per scoprirne il nome esatto e mostrarle con la limpidezza e la trasparenza del cristallo, e non più "per speculum in aenigmate" (1Cor 13, 12). Il fuoco è ciò che trasforma la realtà in parola poetica, quindi nella sua verità.

L'exceso è l'ardore eccessivo ("ardor sobrado") della forgia che è la poesia nel suo ruolo di nomenclatrice del mondo, alla ricerca della coincidenza delle cose con il loro nome, e la barriera di fuoco luogo proprio del maestro dell'inventio poetica, Dante, che infatti resta incolume ("de Dante, ni un cabello/ quemó"). 
L'intuizione delle fiamme presentidas provoca un senso di soffocamento, causando un'arida impossibilità di parola (fisicamente percepibile nella secchezza dell'occlusione velare, del tratto fricativo delle consonanti e dell'incespicare delle dentali: "garganta", “sofocar", “sus presentidas llamas"). Non l'esperienza fisica del calore, ma un sentimento anticipato, divinazione del fuoco di verità che è la parola, soffoca la gola per la percezione di ciò che la barriera di fuoco nasconde. È lo spasimo dell'esperienza mistica di un Amore violentissimo e totalizzante, vòlto a qualcosa di non conosciuto con la ragione, non visto ma solo presentito, quindi ancora temuto. (Anche Dante indugia davanti alla cortina di fuoco del ventisettesimo canto del Purgatorio nel timore di compiere il passo decisivo, fino a quando non apprende che Beatrice è oltre quella barriera).

Dante è dunque colui che "al final entró", cioè il portatore del supremo coraggio della Verità, figura emblematica di chi si assume il rischio del passo decisivo della conoscenza e della poesia senza timore di bruciarsi. Per questo Dante si innalza al ruolo di "duca" dell'anima nell'esperienza dell'oltre: “de tu mano/ más feliz que de Ulises el gobierno- / llegué al opuesto lido" (A Dante Alighierí). La "última cornisa" è il momento fatale in cui compiere el paso más. Il mondo è vissuto come ineludibile scelta, tra il rischio della conoscenza, oppure il passo indietro nel silenzio delle cose conosciute.

L'attraversamento del fuoco "sin temor de apagarlo ni arder", come Dante "casi al final de la ascensión", in un processo di ascesi per conquistare la verità, è anche decretato da Hermes, il dio psicopompo, che, appunto, traduce le anime "al opuesto lido", come condizione necessaria, unica via ("sólo") per giungere a vestire la tunica trasparente degli dèi, per imparare la scienza dell'essere e del non essere ("es y no es") che riporta all'Eden primigenio "donde todo verde es vergel", luogo privilegiato in cui l'uomo è nomenclatore della realtà e detentore dell'Ursprache ormai preclusa ai mortali, la lingua della comunicazione tra l'uomo e Dio che fu negata alla discendenza adamitica a causa del peccato originale. $\grave{E}$ il dominio

${ }^{6}$ Da Parnaso Confidencial (1971-1995), in Poesía 1996, tomo 2, p. 285. 
linguistico - a cui il poeta accede attraverso il fuoco e l'ascesi - in cui, abolita la condanna all'inadeguatezza della parola, la lingua si scioglie ("se discurre") in un flusso che sa dell'essere e del niente ("por el que fluyen nada y ser"). Questa è l'esperienza simbolica espressa nella poesia Palabra de Hermes ${ }^{7}$ :

Sólo acercándose a la llama

sin temor de apagarla ni arder;

entrando, como Dante, en la hoguera

casi al final de la ascensión

o (mejor) en el río de fuego

que eternamente es y no es:

\author{
sólo así se viste la túnica \\ que viste, transparente a un dios, \\ se escala la escala del monte \\ donde todo verde es vergel \\ o (mejor) se discurre en el río \\ por el que fluyen nada y ser.
}

La "parola di Hermes" è un Diktat sulla soglia dell'oltremondo, nel momento in cui il dio si accinge a trasportare le anime all'altra sponda. Siamo davanti ad una poesia sul limite della possibilità tra la "nada" e il "ser". La condizione dell'uomo, tra l'essere e il nulla, è drammatica tensione contraddittoria di estremi che si negano a vicenda, nell'urgenza e nel timore di una scelta. Dante è l'uomo per eccellenza, capace del rischio dell'opzione e di quello del fuoco - misura della dignità e della statura umane - traghettatore delle anime che scelgano di seguirlo. Il timore di ardere impedisce l'esperienza del fuoco ed è perciò fatale, perché essa costituisce l'unica via alla trasparenza della tunica degli dèi ("sólo" e "únicamente" sono avverbi insistentemente collegati al fuoco in tutta la raccolta cui appartengono i due testi citati, Ocupación del fuego).

La perennità del dilemma ("eternamente") dell'essere o non essere si esprime efficacemente nell'atemporalità dei verbi all'infinito e gerundio delle prime tre coppie di versi ("acercándose", "apagarla", "arder", "entrando"). Nei presenti impersonali dei versi successivi ("se viste", "se escala", "se discurre"), che esprimono il tono perentorio dell'enunciazione divina, ed in forte contrasto con la scomparsa del soggetto agente, la "nada" ed il "ser" si affermano nel loro fluire eterno come unici soggetti del testo, allegoria essenziale della dialettica di vittoria e sconfitta tra l'essere ed il nulla.

\footnotetext{
${ }^{7}$ Da Ocupación del fuego (1986-1989), in Poesía 1996, tomo 3, p. 230.
} 
Il movimento di ascensione, ribadito quattro volte nel testo ("al final de la ascensión", "se escala la escala del monte") rimanda direttamente al Purgatorio dantesco; richiamando al cammino ascensionale del mistico pellegrino ed a quello delle anime purificate ("en la primera cantiga, lo que se arrastra; en la segunda, lo que asciende ${ }^{\prime \prime}$ ), confermando il valore catartico dell'esperienza del fuoco e della sequela di Dante.

Il significato di catarsi è ribadito nel Homenaje a Dante, de su traductor ${ }^{9}$ dove si legge un'invocazione del poeta al "duca suo":

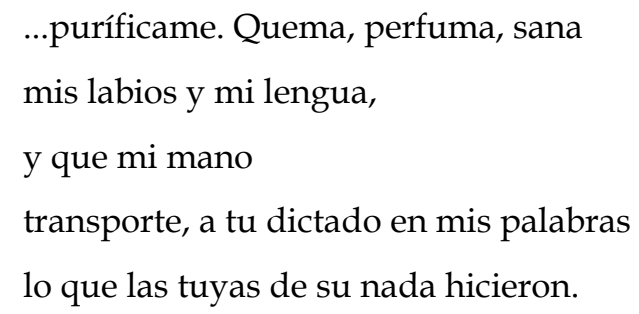

La compagnia catartica di Dante coincide qui con la possibilità di poesia, mentre l'immagine del poeta che purifica l'altro riflette l'immagine di Virgilio che, bagnatosi le mani di rugiada, deterge il viso di Dante della sporcizia infernale prima di entrare nel Purgatorio. Siamo così portati nell'ambito sacrale e vocazionale della poesia, con un rito iniziatico in cui il poeta riceve dal maestro l'unzione col crisma profumato che guarisce col fuoco ("quema, perfuma, sana"), sanando la lingua del poeta dall'inadeguatezza cui la parola umana è condannata nella sua condizione di approssimazione difettosa all'essere. Rivive qui l'immagine del poeta-scriba che ha trovato la sua immortalità nei versi di Dante: "I' mi son un, che quando/ Amor mi spira, noto, e a quel modo/ ch'e' ditta dentro vo significando" (Purg. XXIV, 52-54). Nell'immagine dantesca il poeta scrive sotto la dettatura d'Amore. Nel testo crespiano il dettato del padre della poesia italiana infonde lo spirito poetico alle parole. Le parole del maestro si pongono quindi all'origine (“hicieron”, nel passato remoto delle origini) della propria parola come spartiacque tra il niente ("su nada") e

\footnotetext{
${ }^{8}$ Cfr. Ángel Crespo, Dante y su obra, cit., p. 129.

${ }^{9}$ Da Homenajes (1971-1978) in Poesía 1996, tomo 2, p. 451.
} 
l'esistenza, garanti dell'esistenza stessa della parola e mimesi del gesto divino della creazione ("hacer" è il verbo della corporeità dell'atto produttore di vita). La mano del poeta ("mi mano") si fa strumento dello spirito d'Amore, veicolo fisico dell'eredità poetica dantesca, assumendo così la capacità divina di creare l'essere dal niente.

Pare, in questa grande possibilità di dire, di trovare rimedio alla disconformità con il mondo che mai abbandona il poeta-straniero: nella poesia Dante Alighieri10, le parole del poeta, trasformandosi in mura della città ("las paredes llenas de sus palabras") costituiscono un ambiente eletto in cui è alleviato il peso dell'estraneità dell'esule ("casi extranjero").

\footnotetext{
La tarde inevitable y el poeta

casi extranjero - una edición

en biblia, las paredes

llenas de sus palabras -, y no había

quien le abriese las puertas

de la ciudad (y ni
}

\author{
siquiera era de aquí: le tengo visto \\ tras las ventanas de mi pueblo) \\ para que se enterrase \\ entre el sol y la sombra \\ y no me lo topara ahora yo \\ saliendo del Infierno.
}

Il poeta è lo straniero a cui è interdetto l'ingresso ad una città che pure è costruita dalle sue stesse parole ("las paredes llenas de sus palabras") destinate inevitabilmente ad un'estraneità, a restare extra moenia. La fatalità dell'emarginazione ("inevitable") respinge il poeta nell'estraneità, relegandolo fuori dalle mura cittadine. Il poeta è "quasi straniero": neanche l'unico attributo che gli si riferisce giunge al suo compimento. Lo stesso senso di un compimento mancato si legge nel fatto che a questo soggetto non si riferisca nessuna azione attiva che ne rilevi la vita, ma che resti anzi schiacciato dalla sentenza "inevitable" del suo essere straniero ed incompleto ("casi"), che lo relega al di fuori di pareti costruite dalle sue stesse parole ("las paredes llenas de sus palabras") e lo condanna ad un'esistenza umbratile in negativo ("ni siquiera era"). "Non era neanche" è la condanna del non essere riconosciuti come appartenenti alle mura della propria città, del rimanere "dietro le finestre" senza poter entrare, e privati del proprio possesso. Le "palabras", unico

\footnotetext{
${ }^{10}$ Da En medio del camino (1949-1970), in Poesía 1996, tomo 1, p. 265.
} 
patrimonio di chi "neanche era", restano all'interno di porte che nessuno apre al poeta perchè la sua stessa gente non lo riconosce e lo scaccia. È il dramma della dimora interdetta ("no había/ quien le abriese las puertas") per cui il soggetto che non può trovare pace o dimora viene negato ("ni siquiera era"). Il desiderio del poeta sarebbe quello di "enterrarse" ("para que se enterrase/ entre al sol y la sombra"), radicarsi nella terra, anclar los pasos, o meglio anclar la vida11, su un suolo che gli sia conforme.

Eppure la contropartita, quasi insperato premio, di questa emarginazione è proprio l'universalità del poeta, il suo non conoscere confini ("le tengo visto/ tras las ventanas de mi pueblo"), e di conseguenza un allargamento universale delle mura stesse ad una koinè artistica oltre il tempo e lo spazio. Afferma lo stesso Crespo in uno dei suoi aforismi12: "sólo quienes han vivido siempre en su país son capaces de pronunciar la palabra extranjero".

La poesia A Dante Alighieri13, in cui il poeta assume in proprio il patrón metrico dantesco in una mimesi di voce e di canto, mi pare la sintesi emblematica del significato che la figura di Dante assume nella poesia di Ángel Crespo:

\footnotetext{
Tras del secreto y circular verano adversario del sol, y del invierno que no obedece al Toro, de tu mano - más feliz que de Ulises el gobierno llegué al opuesto lido, y en la orilla donde se hace estación lo que era eterno vi las hacinas de la santa trilla ya sin la paja, todas destinadas tras la molienda a la candida cilla; y vi, tras escuchar voces amadas
} y hollar del hombre la mansión primera, a Beatriz y a las almas transmutadas. A Dios no vi, porque mi vista no era como la tuya inmune a lo divino, mas hice a mi palabra que fingiera con tanto amor tus versos, que el Destino no ha de impedir que estemos frente a frente cuando haya andado todo mi camino: y ya no sé vivir entre mi gente.

\footnotetext{
11 Cfr. Anteo Errante in Juego de sombras (1979-1984), in Poesía 1996, tomo 3, p.163.

12 Á.Crespo La puerta entornada. Aforismos, ed. La Palma, Madrid 1998, p. 16.

13 Da Parnaso Confidencial (1971-1995), in Poesía 1996, tomo 2, p. 285.
} 
Il senso dell'oltre significato nella preposizione tras (che ricorre tre volte nel testo, o meglio quattro, considerando il trans di “transmutadas") trasferisce la poesia in un ambito di riferimento che trascende il mondo noto ("secreto") in una navigazione "di retro al sol" ("adversario del sol”) come quella tentata da Ulisse oltre le colonne d'Ercole, descritta da Dante a rappresentare lo spirito indomito dell'uomo ed il suo infinito spasimo di conoscenza. Non è un caso, infatti, che in questo testo sia citata la figura dell'Ulisse dantesco, anima "transmutada" - termine che rimanda alla tematica delle metamorfosi - proprio in lingua di fuoco, e figura di ardore conoscitivo, di "non domato spirito" (Saba). La mano di Dante (senso salvifico dell'agape artistica), si mostra strumento più saldo e timone migliore di quanto non lo sia stato il "picciol legno" con cui Ulisse aveva intrapreso il viaggio: è esplicita qui la funzione di “duca" dell'anima (psicopompo) di cui Dante è investito.

L'immagine della santa trebbiatura ("santa trilla"), nella metafora del mulino trascendente, rappresenta proprio la metamorfosi e la catarsi delle anime che, attraverso la molitura ${ }^{14}$, vengono consacrate, in quanto la molitura rende il grano MOLA cioè farina con cui si cosparge l'offerta sacrificale, quindi purificate ("cándida") e destinate alla redenzione finale.

Il paradiso crespiano appare come l'attuarsi di ciò che è in potenza, e il ritrovamento della "mansión primera", dimora originaria dell'uomo, prezioso palazzo della coincidenza armonica delle forme, non della disconformità dell'eccesso che sarebbe morte, ma della sosta ${ }^{15}$ ricreativa al termine di un lungo viaggio. Nella pace della sosta diviene finalmente possibile il dialogo ("escuchar voces amadas") come "celeste $[\ldots]$ corrispondenza d'amorosi sensi".

\footnotetext{
${ }^{14}$ Molienda, dal lat. MOLENDA < MOLO, macinare, girare la mola. Il termine MOLA, oltre a designare la macina del mulino, indica la MOLA SALSA, cioè il miscuglio di farro macinato e sale che si spargeva sul capo della vittima del sacrificio, da cui IMMOLO, sacrificare. (Cfr. Moliner, s.v. molienda).

${ }^{15}$ Mansión, dal latino MANSIO, ONIS < MANEO, contrario di DECESSIO, EXCESSUS, indica la sosta dopo il viaggio, la casa. Oggi in spagnolo ha assunto l'accezione di dimora nobiliare. (Cfr. Moliner, s.v. mansión).
} 
Se poi il destino finale dell'uomo è premio e conseguenza della sua vita, per il poeta, amoroso fictor della parola dantesca il premio alla fine del pellegrinaggio terreno, sarà poter stare "frente a frente" con Dante, parametro di una forte centralità umana politica e morale dell'uomo che realizza appieno l'Humanitätsideal crespiano della "poesía en su aire".

I due versi finali riportano il ritmo difficoltoso dei passi dell'esule nella durezza dell'occlusione consonantica ("cuando haya andado todo mi camino") e la drammatica incapacità di appartenere alla propria gente ("y ya no sé vivir entre mi gente"), riproponendo così la fatica dell'esilio e dell'incapacità del poeta a vivere in mezzo al suo popolo. Ma il "no sé vivir" accenna forse ad una sorta di deliberata scelta del poeta di non appartenere ad alcun popolo: in questo consiste la sua universalità, nel non conoscere i confini della propria terra (la limitata tranquillità dell'età aurea in cui "nulla mortales praeter sua litora norant"16, gli sarebbe senz'altro insoffribile). Del resto è un'affermazione di Ángel Crespo che i veri poeti non debbano avere patria politica o razziale ("son gente aparte"17), ed è pure vero che uno dei grandi valori di Dante è l'universalità, e la traduzione crespiana della Commedia, parte di un progetto di valorizzazione della cultura spagnola mediante la sua integrazione nella cultura universale ${ }^{18}$. Si tratta di un reale ecumenismo come creazione di un oikuménè poetico totale. La mansión desiderata non si intenda allora, mai come spazio delimitato in cui stanziarsi, ma come superiore unità di ordine culturale ed artistico di coloro che riconoscono senza riserve la "indisputable forma humana"19, che si realizza nell'ambito della forma espressiva dell'arte.

\footnotetext{
${ }^{16}$ In Ovidio Metamorfosi I, 96,

17 Ángel Crespo, Los trabajos del espíritu, Diarios 1971-72 / 1978-79, Seix Barral Biblioteca Breve, Barcelona 1999, p. 335

${ }^{18}$ Cfr. Pilar Gómez Bedate, Para un estudio de la poesía comprometida de Ángel Crespo, in Ángel Crespo: una poética iluminante, BAM, Ciudad Real 1999, p. 129.

${ }^{19}$ Cfr. Ángel Crespo, Exilio y abismo, in DD. AA. El tiempo en la palabra, "Anthropos", Suplementos n. 15, giugno 1989., p. 104.
} 
La Poesia e l'Esilio, dunque, la prima a costo del secondo, uniscono in un comune destino Dante ed Ángel Crespo e fondano la paternità d'elezione di cui il “florentín viajero" è fatto oggetto da parte del poeta esule spagnolo.

Questa paternità emerge nei diarî crespiani come un'osmosi data dalla lunga frequentazione, che è addirittura normativa per la vita. Si legge in data 22 aprile 197920:

"L'uomo bono dee la sua presenza dare a pochi e la familiaritade dare a meno, acciò che '1 nome suo sia ricevuto ma non spregiato" (Dante, Convivio, I, IV, 11). Nunca me ha costado trabajo actuar según esa norma.

Il Convivio è cioè, espressione delle norme più confacentesi all'umanità del poeta, e l'umanità di Dante paradigma supremo.

\section{Memoria poetica e tracce dantesche}

\section{Scrive Octavio Paz:}

Traducción y creación son operaciones gemelas [...] hay un incesante reflujo entre las dos, una continua y mutua fecundación. [...] Las obras, todas arraigadas a su suelo verbal, son únicas; únicas pero no aisladas: cada una de ellas nace y vive en relación con otras obras de lenguas distintas $^{21}$.

Questa convinzione appartiene anche all'esperienza crespiana di poeta e traduttore. Nel Apunte finale alla prima edizione della raccolta poetica El bosque transparente ${ }^{22}$, Ángel Crespo scrive:

\footnotetext{
20 Ángel Crespo, Los trabajos del espíritu, cit., p. 219.

${ }^{21}$ Octavio Paz, Traducción, imitación, originalidad in "Cuadernos Hispanoamericanos", n. 253-254, gen.feb. 1971, p. 14 .

${ }^{22}$ El bosque transparente, pubblicato a Barcelona nel 1983 da Seix Barral, è una seconda "obra completa" crespiana (dopo En medio del camino 1949-1970, Seix Barral, Biblioteca Breve, Barcelona 1971) e raccoglie la poesia del decennio creativo 1971-1981. I libri che compongono questa raccolta, dei quali era inedito solo il Libro de Odas, sono: Claro:Oscuro (1971-1975), Porvivir Independiente, Zaragoza 1978; Colección de climas (1975-1978), Aldebarán, Sevilla, 1978; Donde no corre el aire (1974-1979), Vasija,
} 
mi larga intimidad con la obra del florentino, así como los estudios que hube de hacer para lograr una mejor comprensión de sus proposiciones, me impulsaron a tratar de profundizar de una manera que, hoy por hoy, considero irreversible una visión y comprensión de las cosas que ya se había iniciado en mi obra anterior, y a la que la crítica había dado el nombre de realismo mágico ${ }^{23}$.

Il costante reflusso dall'operazione del tradurre al processo di crezione poetica, viene documentato dalle affermazioni di Crespo stesso. Proprio nel pieno dei lavori di traduzione il poeta scrive al suo editore Gimferrer:

mi poesía va cambiando tanto que casi no me atrevo a dar muestras en revistas, y, de momento, no lo hago. No es que cambie en otra dirección pero creo que estoy sacando ahora las difíciles consecuencias de cuanto he hecho en poesía antes de ahora²4.

La poesia crespiana è infatti potentemente sommossa dall'immersione nella parola dantesca. Ancora, in una lettera di presentazione di Claro: Oscuro a Pedro Gimferrer, Crespo parla in questi toni del suo lavoro di poeta:

te envío Claro: oscuro. [...] Le he dado vueltas y vueltas, como si fuese un escritor novel, he ordenado y reordenado los poemas. Creo que su disposición actual es la más conveniente, pero ¡cuánto me ha costado darla por definitiva! Sólo uno de los poemas - el último - ha sido publicado y el resto es rigurosamente inédito. Mi ilusión sería aportar algo nuevo, al cabo de seis años de no publicar un libro de poesía y de haber trabajado enormemente sobre este puñado de poemas. Jamás he puesto más ilusión en un libro mío. Me he entregado por completo a las virtualidades, al poder de la palabra poética. Quiero decir que es un libro sin prejuicios, o quizás con el único prejuicio de que la palabra poética lo puede todo. No sé si lo habré conseguido 25 .

La lunga gestazione dell'espressione del proprio messaggio poetico, parallelo all'attività di traduttore, è dunque il tempo del continuo lavorio sulla parola, come materia da plasmare fino a renderla perspicua, capace di penetrazione nel mistero

Sevilla 1981; Libro de Odas (1977-1980); El aire es de los dioses (1978-1981), Olifante, Zaragoza 1982. Nella poesia completa del 1996, El bosque transparente costituisce il nucleo centrale del tomo 2.

${ }^{23}$ Á. Crespo, Apunte a esta edición in El bosque transparente, cit., p. 206.

24 Á. Crespo, lettera a Pedro Gimferrer da Mayagüez, 29 settembre 1973 (inedita).

25 Á. Crespo, lettera a Pedro Gimferrer da Mayagüez, 15 gennaio 1976 (inedita). 
delle cose, e per ottenere da questa parola ispirata che il mondo le si consegni nel suo significato.

Al termine del lavoro di traduzione, e dopo la pubblicazione della terza cantica, Crespo scrive queste parole che mi paiono estremamente significative:

Anteayer me llegaron los ejemplares del Paraíso. Estoy muy contento de que hayamos dado cima a esta edición, que creo que ha quedado muy bien. Creo que con ella he cubierto una etapa, no sólo de traductor sino de mi propia poesía: tan identificado me siento con esos $\operatorname{versos}^{26}$.

Il culmine del lavoro di traduzione ha portato ad un'identificazione del traduttore con i versi tradotti: questo significa un'interiorizzazione profonda di ogni verso dantesco con cui il poeta traduttore si è singolarmente misurato, desentrañando il significato di ogni parola di Dante per restituirla nel modo più completo possibile al sistema linguistico spagnolo. Un'interiorizzazione tanto profonda implica certamente un punto di non ritorno nell'arte poetica crespiana.

Nella poesia di Ángel Crespo, la presenza dantesca è decisiva fin dalla prima raccolta poetica del 1971, anno in cui Crespo si vedeva già impegnato nell'inizio della traduzione della prima cantica della Commedia. Nel titolo En medio del camino, dove la citazione del primo emistichio della Commedia corrisponde alla trasposizione che ne fa Francisco Imperial nel suo Dezir a las syete virtudes, Crespo richiama un Dante già incorporato nella tradizione letteraria spagnola. In questo titolo della prima "obra completa" crespiana, le parole dantesche assumono una risonanza esistenziale, oltre che prettamente artistica di un suma y sigue nel proprio cammino di vita, di poesia e di un esilio che dura già da quattro anni, nel segno della "verità del sacrificio di Dante, $[. .$.$] l'uomo che prova personalmente gli scontri con il reale e li risolve in$ valori etici di alta durata estetica" 27.

\footnotetext{
26 Ángel Crespo, lettera a Pedro Gimferrer da Mayagüez, 30 ottobre 1977 (inedita).

27 Gaetano Chiappini, Nota sulla poesia di Ángel Crespo, in Ángel Crespo, Autolettura a Parma, “L'Albero", n. 68, Lecce 1982, p. 48.
} 
La traduzione della Commedia apporta problematiche e campi semantici nuovi all'opera crespiana. La rielaborazione ed appropriazione della poesia dantesca da parte del suo traduttore, avviene secondo diverse modalità in un sistema di memoria che riprende, di testo in testo, moduli linguistici di origine dantesca nella forma della citazione, come un intenzionale e dichiarato rimando intertestuale oppure trasformati, cioè inseriti vivamente e metabolizzati dall'interno. Si tratta di riscontri lessicali, ricorrenze di termini particolari che possono ampliarsi a includere da una singola parola, a un intero sintagma. Altre volte la memoria del traduttore si manifesta come ricreazione di immagini riconducibili a quelle dantesche.

I casi più manifesti in cui la poesia crespiana evoca vivamente figure della Commedia, ricreando una situazione poeticamente nuova ma geneticamente riconducibile alla memoria dantesca, sono quelli delle poesie Fuegos de Islandia e Metáforas del ausente.

L'immagine, dantesca al pie de la letra, dell'anima che corona la sua ascesi con la conquista del Paradiso appare rivissuta nella poesia Fuegos de Islandia ${ }^{28}$, che risale appunto agli anni in cui Crespo è impegnato nella traduzione della Commedia. Cito la seconda parte del testo:

\footnotetext{
Como el pájaro llega

a donde se resiste la mirada,

roza las llamas, y otra cosa no

puede llevarse sino la aventura

fénix, sino la herida

herida al aire angosto;
}

\author{
así al sobrevolar \\ el cráter a que un triste \\ viento sin centro sin cesar me empuja, \\ lanzo un grito de miedo y de victoria: \\ como un alma que gana el paraíso.
}

La mancanza di aria ("aire angosto") e il fuoco sono le condizioni per il processo di trasformazione degli elementi nell'alambicco, quindi è l'anima-pájaro del poeta ferita dal desiderio (da notare la ripetizione in enjambement del termine "herida") che si fa ave fénix per incendiarsi senza estinguersi ("roza las llamas") per poter giungere oltre il visibile ("llega / a donde se resiste la mirada") ed ottenere un

\footnotetext{
${ }^{28}$ Da Colección de climas, in Poesía 1996, tomo 2, p. 85.
} 
grado di conoscenza superiore, propriamente la perspicuitas paradisiaca. Le condizioni attraverso cui si ottiene questa perspicuitas sono quelle dell'estremo rischio ("aventura") del fuoco sulla montagna (cratere del vulcano, ma anche memoria della barriera di fuoco dell'ultima cornice del Purgatorio nel canto XXVII), destino ("ADVENTŪRA" andare incontro alle cose che verranno) di rinascita dalle proprie ceneri (la fenice) in una maggiore saggezza, esperienza purgatoriale di sacrificio estremo del sé e ritrovamento della propria individualità incrementata dalla conquista del Paradiso ("alma que gana el paraíso"), aconfessionalmente inteso come vetta infuocata ("cráter") della propria ascesi spirituale. La purificazione del fuoco è l'unico capitale che può ottenere ("otra cosa no / puede llevarse") il poeta-pájaro nel suo volo estremo, anche grazie all'esperienza di un infernale "triste / viento sin centro" che trascina l'anima del poeta verso il cratere "sin cesar" (ricorda la "bufera infernal che mai non resta" che trascina le anime dei lussuriosi in Inf. $\mathrm{v}, 31$ ).

Nella poesia Metáforas del ausente ${ }^{29}$, un testo del 1978, anno successivo alla prima edizione della traduzione del Paradiso, l'esperienza dell'esilio, la sofferenza per l'ingiustizia subìta e la poesia come via salvifica opposta all'angoscia della solitudine e dell'incomprensione, vengono descritte da Crespo in termini che evocano da vicino quelli danteschi:

El exilio no es una carga:

por ejemplo, una cruz, un saco roto

del que se caen las piedras y está lleno

siempre; ni es una puerta,

ni un muro en el que todas

las salidas se estrellan, ni un canal

que se lleva las barcas y los versos.

Es más bien como una

niebla sutil que cubre cuantas almas

y cuantos gestos, una

nube implacable que se llama niebla

y otros llaman exilio.
Envuelto en ella - siempre -,

una alfombra se pisa de hojas secas,

se bebe un agua tibia, un vino escaso

que más parece almagre,

se come un pan que huele

a muchas manos - siempre

lavadas y secadas en exceso-,

se duerme entre la mar y la vigilia,

pendientes - siempre - de lejanas torres

que nunca dan la hora;

sentados - siempre - en el brocal de un pozo.

${ }^{29}$ Da Colección de climas, in Poesía 1996, tomo 2, p.97. 
La definizione crespiana dell'esilio, possiede come prima caratteristica la privazione dell'essere. Innanzitutto "el exilio no es", è dunque privo di qualsiasi realtà o identità, è un niente "implacable" che annienta tutto ciò con cui entra in contatto. A questo niente, che tutto priva di verità, sarebbe pure preferibile un peso da sopportare, che, anche paradossale ("saco roto / del que se caen las piedras y está lleno / siempre"), è pur sempre segno di vita, o almeno di espiazione e recupero di vita, come nella cornice dei superbi del Purgatorio. L'esilio non è una porta, cioè elimina la comunicazione; il suo essere nocivo consiste nel fatto che non è qualcosa con cui ci si può scontrare o contro cui lottare ("un muro en el que todas / las salidas se estrellan"). La negatività dell'esilio è quindi proprio il suo alienante non essere, nebbia o nube di cui neanche il nome è certo ("nube implacable que se llama niebla / y otros llaman exilio"), che copre, cancellandoli, le anime e i volti, cioè oblitera l'essere di tutto ciò che tocca. L'esule, chi vive avvolto, preso d'assedio della nebbia del non essere, è defraudato dell'essenziale: l'acqua tiepida non disseta e provoca la nausea, come il vino ossidato ("almagre"), mentre il gesto della comunionalità per antonomasia, le mani che offrono il pane, perde la sua essenza e diventa menzogna, perché le mani hanno smarrito ogni carnalità e sono aride e asettiche mani di automi ("lavadas y secadas en exceso"). Qui riecheggia il dramma dantesco profetizzato da Cacciaguida in Paradiso XVII, 59 del "pane altrui" che "sa di sale". Il riposo degenera in un'agitata sospensione ("se duerme entre la mar y la vigilia") senza nessuna possibile coordinata temporale ("pendientes - siempre - de lejanas torres / que nunca dan la hora") condanna ad una perenne (l'avverbio "siempre" si ripete due volte) instabilità nel rischio di essere risucchiati nella gola del non essere ("sentados [...] en el brocal de un pozo"). Il titolo stesso dice di questo dramma dell'essere negato: l'esule è el ausente, cioè colui che è assente dalla sua terra, e, più profondamente, qualcuno che non $\mathrm{è}^{30}$.

\footnotetext{
${ }^{30}$ ABSENS, ABSENTIS, participio presente di ABSUM, significa anche propriamente il non esserci, essere estraneo.
} 
Per quanto riguarda la ripresa lessicale di elementi della Commedia, nella poesia crespiana cronologicamente parallela alla traduzione, la memoria dantesca emerge in diversi casi.

In Solitario por Roma, una poesia contemporanea a quelle raccolte in El bosque transparente, il poeta caratterizza la sera romana con lo strano termine di gelatina. Nella Commedia il termine gelatina compare una sola volta ${ }^{31}$ - di qua la sua notevole peculiarità - a designare la zona ghiacciata dalle ali di Lucifero del lago Cocito. Nella citazione crespiana, il termine gelatina viene inserito in un ambito gnoseologico:

en plena lucidez de solitario, entre almacenes y palacios idos -y entre los restos de la prensa gialla, algunos de ellos voladores, entre la gelatina del anochecer y el ruido imaginado de la piedra, a las calles de la Urbe voy cosido ${ }^{32}$.

Il ghiaccio metafisico dantesco diventa uno stato di eccezionale lucidità ("plena lucidez"), il poeta, in uno stato privilegiato di solitudine ("solitario") si trova fissato ("cosido") allo spazio della concinnitas classica ("las calles de la Urbe") dalla cristallina trasparenza del ghiaccio, che rende geometricamente chiara la notte romana, in cui infatti si produrrà la rivelazione della nudità della Venere anadiomèné33.

Ancora lo stesso termine si ritrova in Contra el futuro 34 , dove appaiono "tambores de gelatina".

\footnotetext{
31 Inferno XXXII, 60: "tutta la Caina / potrai cercare e non troverai ombra / degna più d'esser fitta in gelatina".

32 Solitario por Roma, in Poesía 1996, tomo 2, p. 447.

33 Il poema in prosa citato si conclude cosí: "tu cuerpo desnudo y tú desnuda [Venus anadiomena] estáis junto a mí para entregarme la Verdad: que desmiente las ruinas". L'apparizione di Venere anadiomèné riveste il significato di una rivelazione teofanica: "Afrodita anadiomena es la que sale del baño, del agua de la que se genera la vida. [...] Es la Afrodita total, la que representa todas las formas posibles de Amor y, en consecuencia, de vida." Ángel Crespo, Notas para una lectura alquímica de las Metamorfoses de Jorge de Sena, in ID. Por los siglos (ensayos de literaturas europeas), Pre-textos, Valencia 2001, p.214.

${ }^{34}$ Da Claro: oscuro, in Poesía 1996, tomo 2, p. 50.
} 
¿Qué del futuro? [...] ¿Qué podrán hacerme aprender su lenguaje de algas o piedras tristes, su música de pífanos torcidos o de tambores de gelatina? [...]

In questo caso, i "tamburi di ghiaccio" insieme a "pifferi contorti" costituiscono la voce ambigua di un futuro ignoto e temibile, linguaggio impossibile ("de algas o piedras") che non corrisponde alla possibilità di comprensione umana ("qué podrán hacerme aprender"), un linguaggio e una musica dai quali non è possibile ricavare conoscenza. Inoltre il corredo genetico del termine introduce la connotazione dantesca del ghiaccio infernale ed eterno, luogo più prossimo allo 'mperador del doloroso regno, diametralmente opposto alla luce salvifica della conoscenza perfetta del Paradiso.

A conclusione di un lungo poéme en prose intitolato La palabra $\mathrm{No}^{35}$, appartenente anch'esso al gruppo di poesie contemporanee a quelle raccolte in $E l$ bosque transparente, si legge:

[...]La palabra No tiene la virtud de despertar: entre los dos vacíos que la modelan - el de la nada y el de la eventualidad del poema - la palabra No posee un rostro casi afirmativo. [...] Resulta, además, que la poesía se desarrolla en una sola y miserable dirección por el lado del Sí, mientras se abre en ilimitadas posibilidades expansivas por los misteriosos caminos del No (que lleva implícito un insidioso Sí). [...] De aquí puede y debe deducirse que la poesía gira siempre en las esferas del No, aun cuando su naturaleza sea afirmativa, igual que el sol y las demás estrellas.

Dove riecheggia evidentemente il verso "aquel amor / que mueve el sol y las demás estrellas", che è proprio la traduzione crespiana del sublime verso finale della Commedia: "amor che muove il sole e l'altre stelle". La figura della negazione, si sostituisce dunque, nella mente poetica crespiana, alla forza motrice dell'Amore divino, ed è quindi istituita a primo motore e forza creatrice dell'universo. Essa costituisce infatti la categoria della pura potenzialità creativa in quanto la sua struttura "está modelada por dos vacíos [...] el de la Nada y el de la eventualidad del poema". La parola No, è quindi lo spazio privilegiato della possibilità, sfida radicale dell'estrema eventualità che il poeta possiede di parlare e quindi di esistere e di

35 In Poesía 1996, tomo 2, p. 433. 
riscattarsi dal niente che annichila. Essa è la dimensione propria dell'operare paradossale e demiurgico - creare dall'assenza del creato - cui il poeta è potentemente chiamato dalla stessa esistenza della pura possibilità, che "tiene la virtud de despertar". E il vuoto è l'estremo rischio del poeta, alternativa tra l'inesistenza e la poesia.

Ancora nell'ambito della memoria dantesca, un verso delle Teofanías ${ }^{36}$ recita quanto segue: “de verso a verso / hay un vacío, [...] ya lo quieres / pasar, pero el pulso te tiembla" che richiama la paura di Dante "ella mi fa tremar le vene e i polsi" in Inf. I, 9037, quando alle pendici del "dilettoso monte" la lupa gli impedisce il passaggio dalla selva oscura alla luce della cima del colle illuminato dal sole. La paura che paralizza Dante davanti alle tre fiere si pone quindi come segno di riconoscimento del tremore del poeta traduttore, e profondo lettore delle parole dantesche, che ne riattualizza il significato all'interno della sua personale ascesi artistica sul rischioso discrimine tra l'avventura della conoscenza dell'ineffabile e il caos della selva oscura

\section{Itinerarium mentis}

Dopo aver individuato alcune referenze dell'attuare della memoria dantesca nella poesia crespiana, si passa qui alla ricerca delle traccie di quel "irreversibile approfondimento" dovuto alla lunga frequentazione dantesca che Crespo stesso legge nella sua poesia. Presupponendo comunque la profonda discrasia che esiste tra il grande poema dantesco, suprema sintesi artistica del mondo cristiano-medievale, e la personale ricerca della lirica crespiana, mi pare di poter individuare qualche non improbabile punto di relazione. Lungi, quindi, dal cercare di operare un insostenibile parallelo tra la Commedia e la poesia di Crespo, si descrivono le caratteristiche che assume la sua indagine poetica nel lasso di tempo in cui questa si affianca all'attività traduttoria della poesia dantesca.

\footnotetext{
${ }^{36}$ Da El bosque transparente, in Poesía 1996, tomo 2, p. 240.

${ }^{37}$ Crespo traduce questo verso con "pulso y venas me han temblado".
} 
Secondo Pilar Gómez Bedate ${ }^{38}$, si afferma nella poesia crespiana degli anni settanta, come strumento di una quête artistica che ha dell'iniziatico l'uso

del lenguaje del esoterismo antiguo y moderno - magia, alquimia, religiosidad mistérica, gnosis, teosofía - que ha empezado a manejar en su obra crítica a partir de la traducción de Dante y de sus estudios sobre el poeta toscano [...]. Pienso que fue la inmersión en lecturas sobre mitología (a que primero le indujo su traducción de Dante y después un curso sobre Mitología y Literatura que propuso en la Universidad de Puerto Rico y luego enseñó durante varios años) lo que trajo, en seguida a su obra las figuras de los dioses antiguos cuyo significado y naturaleza mítica va a tomar como expresión de su vida psíquica.

La poesia di Dante diventa allora sostrato metalinguistico e culturale, veicolo alla conoscenza del linguaggio del mito, ed essa stessa strumento della ricerca gnoseologica crespiana.

Meta reale del viaggio dantesco è l'unità del molteplice in Dio, e, fino alla vetta suprema della rivelazione definitiva, accompagna il pellegrino-poeta la preoccupazione dell'inadeguatezza della parola ad esprimere efficacemente la sostanza dell'essere (Par. XXXIII, 85-90) :

Nel suo profondo vidi che s'interna legato con amore in un volume, ciò che per l'universo si squaderna: sustanze e accidenti e lor costume, quasi conflati insieme, per tal modo che ciò ch'i' dico è un semplice lume.

La meta ideale della ricerca poetica crespiana è poter carpire, attraverso la parola poetica il mistero dell'unità profonda degli esseri e delle cose:

La poesía busca y procura la unidad de todas las cosas. [...] Sólo en el momento privilegiado de la epifanía - el que anuncia o cree anunciar, según los casos la inspiración - se siente esa unidad que, tras mostrársenos, en seguida se nos suele escapar sin dejar otro rastro que el de la palabra poética, si ésta ha sido capaz de semejante prodigio. [...] Lo que yo quiero de la poesía es que me muestre y me enseñe a mostrar a los demás la realidad entera (con su parte

\footnotetext{
38 Pilar Gómez Bedate, Una aproximación a los dioses de Ángel Crespo: de Claro:Oscuro a Ocupación del fuego, in En Florencia para Ángel Crespo y su poesía, atti della giornata di studî, 7 dicembre 1999, Alinea, Firenze 2000, pp. 115-116.
} 
aparente y con la oculta), de manera que concibo a la poesía en su fondo más profundo como un ejercicio de conocimiento por revelación, como una operación mágica. ${ }^{39}$

L'itinerarium mentis crespiano, pellegrinaggio terreno in cerca della complessa unità del molteplice, prende le mosse da una selva. El bosque transparente è la selva come condizione di caos gnoseologico, ma trasparente, quindi un caos che permette l'intuizione di una trascendenza.

L'itinerario della ricerca crespiana è doppio: al pellegrinaggio terreno "tras las huellas más puras / y ardientes de los dioses" 40 , si affianca la discesa nella propria interiorità, descritta con il linguaggio dell'alchimia che, secondo quanto scrive Pilar Gómez Bedate

es el vehículo de un concepto decididamente hermético: el de la metamorfosis personal, la posibilidad de la conversión del hombre en dios. $\mathrm{O}$, más modestamente, el cultivo del germen o la parte de la naturaleza divina que el neoplatonismo admite como existente en la criatura humana con cuyo desarrollo es posible la salvación ${ }^{41}$.

Questa idea della metamorfosi "que Ángel defiende como concepto fundamental del hombre en la Comedia", appare coscientemente nell'universo poetico crespiano, ancora secondo Pilar Gómez Bedate, a partire proprio dal lavoro di interpretazione della poesia dantesca.

La duplice ascesi crespiana, come "dimensione di doppia verticalità, di mutua intesa totalmente perseguita nella correlazione bidimensionale del sé e degli dei" 42 , si sviluppa tra due estremi: l'abisso infernale della solitudine e del silenzio delle cose ${ }^{43}$, da cui si giunge, tramite una profonda speculazione spirituale e l'identificazione con

\footnotetext{
39 Ángel Crespo, Notas Inéditas, in “La Alegría de los naufragios”, n.1-2, anno 1999, p. 29.

${ }^{40}$ Errante, da El bosque transparente, in Poesía 1996, tomo 2, p. 208.

${ }^{41}$ Pilar Gómez Bedate, Una aproximación a los dioses de Ángel Crespo, cit., p. 122.

${ }^{42}$ Gaetano Chiappini, Nota sulla poesia di Ángel Crespo, cit., p.48.

${ }^{43}$ Secondo le parole del poeta stesso, "l'inferno è, certamente, questa vita, alla quale mi sto riferendo [parla dell'esperienza della natura tropicale come di una totalità annientatrice], di solitudine, di silenzio". Cfr. Autolettura a Parma, cit., p. 37.
} 
la parola salvifica, alla perspicuitas luminosa di un mondo che inizia a svelarsi nella sua possibilità di teofania dello spirito. Si possono quindi individuare tre tappe all'interno dell'itinerarium mentis crespiano, certo non come un percorso scandito linearmente, ma che comunque corrispondono ad una logica di Bildung interiore interna alla raccolta poetica, e certamente anche quella di una disposizione fisica delle poesie all'interno della raccolta El bosque transparente, coerente alla volontà artistica del poeta.

Questo itinerario costituisce, del resto, il significato profondo del titolo della raccolta presa in esame:

La palabra "bosque" tiene, en este caso, un sentido [...] de espacio de la vida terrestre y sensible, lugar confuso e inevitable a través del cual el hombre tiene que abrirse camino, con o sin esperanza de trascenderlo; [...] la palabra poética tiende a tornar transparente a ese bosque, a iluminar a lo que hay por detrás de sus apariencias, a familiarizarse con ello de manera que la selva selvaggia y oscura de que habla Dante al principio de su Commedia nos haga maravillarnos, pero no temerla, nos muestre, a través de su aparente confusión, la misteriosa armonía en la que ser y no ser, saber e ignorancia, vida y muerte, nos ayuden - al poeta y a sus lectores - a ser nosotros mismos, a volvernos también trasparentes a nuestras propias miradas interiores ${ }^{44}$

Nella selva selvaggia si svolge la ricerca di una rivelazione poetica che non si ottiene per passiva ispirazione ma grazie alla fatica dell'integrazione nello spaziotempo della cultura. In questo suo uso della poesia come strumento di conoscenza, Crespo si vede inserito in una tradizione lirica, in cui lo precedono tra gli altri secondo quanto afferma egli stesso - Dante, Rilke, Juan Ramón Jiménez e Fernando Pessoa, che "interpreta a la realidad natural como vehículo hacia una síntesis que, sin negarla, la transcienda $45^{\prime \prime}$.

La ricerca poetica prende le mosse dal personale inferno crespiano, l'abisso della solitudine e del silenzio delle cose, in un universo estraneo al "palpito

\footnotetext{
${ }^{44}$ Ángel Crespo, Presentación de El bosque trasparente, appunti autografi del poeta. Inedito.

45 Ibidem.
} 
cordiale" 46 dell'anima del poeta, che corrisponde al mondo statico e congelato dei paesi nord-europei, in cui Crespo trascorse alcune stagioni nei primi anni settanta, e costituisce un capitolo della vita spirituale del poeta come esperienza climaticoesistenziale di deserto interiore.

L'esperienza del silenzio di una realtà ostile, che non cede alle sue profferte amorose, è ciò che preclude al poeta un significante rapporto con le cose, in quanto non corrispondono i codici posti a confronto.

La poesia Bosque de Uplandia ${ }^{47}$ esprime quest'esperienza di alienazione:

Crece el arce indiferente

a mi corazón ausente;

lanzan las aves gemidos,

ajenos a los latidos

de mis sienes, y se mustia

la flor - y no es por mi angustia -

y el agua sigue corriendo mientras no la estoy oyendo.

¿Quién soy, quién somos, ajena

naturaleza, sin pena

ni gloria los dos, al lado

uno del otro, ignorado

nuestro ignorarnos? ¿Qué dios

nos ciega, ciego, a los dos?

Nel paesaggio nordico, esplicitamente caratterizzato (Uplandia, el arce, el Mosela), il non essere ("ausente"), e l'ignoranza (ridondante "ignorado / nuestro ignorarnos"), una mancata "corrispondenza d'amorosi sensi" ("indiferente", "corazón ausente", "gemidos / ajenos a los latidos / de mis sienes", "se mustia / la flor- y no es por mi angustia", "no la estoy oyendo") costituiscono la condanna ad una solitudine alienante e all'impossibilità comunicativa tra il poeta e il cosmo, vissuta come la disperante menomazione fisica della cecità: “¿Qué dios / nos ciega, ciego, a los dos?", tanto più grave in quanto impedisce la visione di questo mondo e dell'altro che esso adombra ("¿qué dios?").

Ancora questa condizione di ignoranza assillante è espressa nella poesia Atardecer junto al Mosela 48

\footnotetext{
46 È un'espressione di Gaetano Chiappini nella sua Nota sulla poesia di Ángel Crespo, cit.

${ }^{47}$ Da El bosque transparente, in Poesía 1996, tomo 2, p. 87.

${ }^{48} \mathrm{Ivi}$, p. 90.
} 


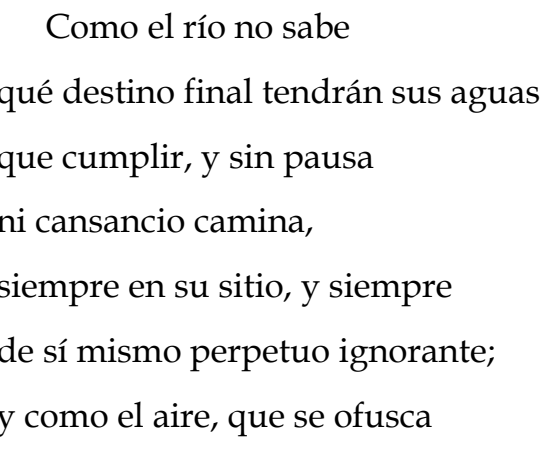

y por el cauce corre, pero tampoco tiene una patria en que posar sus alas de una vez; y como la luz, que ya es y ya no es - ¿y a dónde va, o no será su misma oscuridad? - así mis palabras, que son el otro río.

Preclusione della vista quindi, ma anche della parola: l'ignoranza della meta ("no sabe / qué destino final") priva il poeta delle facoltà di vedere e di esprimersi ("así / mis palabras"), in uno stato ambiguo di intermittente mancanza della luce ("aire, que se ofusca", "luz, que ya es y ya no es"), situazione che ricorda quella infernale del viandante "che visitando [va] per l'aere perso" (Inf. V, 89). Tale condizione di "coscienza fusca" (Par. XVII, 124), implica anche la privazione di "una patria / en que posar sus alas de una vez". Dove si conceda al termine patria il senso di uno spazio privilegiato di possibile corrispondenza interiore, anelata pausa ristoratrice, che il verso rappresenta con una esalazione spossata di sibilanti.

L'insicurezza, derivata dalla mancanza di chiavi culturali per comprendere e interiorizzare il mondo circostante accomuna l'esperienza della natura nordica e di quella tropicale. Così il poeta rivive l'ostilità della natura muta in jEfeta! ${ }^{49}$ :

\begin{tabular}{ll}
\multicolumn{1}{c}{ Salgo a ver las palmeras } & Levanto contra el cielo sus enjambres, \\
de este país. Procuro & suplico su palabra: \\
ganarlas con caricias de mis ojos & - ¡Efeta! (Esto es, ¡Abríos!). \\
y gustar en secreto de sus frutos. & Pero no eran palmeras.
\end{tabular}

L'uscire è l'estasi ${ }^{50}$, l'evasione da sè del poeta totalmente assorbito nel tentativo totalizzante ("procuro": fa tutto il necessario per ottenere ciò che desidera, unica direzionalità dell'agire) di conquistare il gusto segreto dei frutti: ganar esprime tutto lo sforzo del desiderio che conquista l'oggetto grazie alla sua stessa intensità. La

\footnotetext{
${ }^{49} \mathrm{Ivi}, \mathrm{p} .74$.

${ }^{50}$ Estasi dal greco ÉKSTASIS è nome d'azione del verbo EKSÍSTËMI 'essere fuori di sè’
} 
gestualità del poeta si esprime nella sinestesia dove gli occhi acquistano la capacità delle mani di carezzare ("caricias de mis ojos") per raccogliere la realtà in cui si imbatte. Gustare in segreto i frutti è un gesto di assunzione fisica, eucaristica, della materialità delle cose: la realtà di cui si desidera un possesso totale, viene compresa nella sua corporeità nel gesto sensuale dell'assaporare il frutto che essa offre. La parola con cui il poeta si rivolge al brano di realtà di cui chiede la rivelazione, "Effetà", è la parola con cui nel Vangelo di Marco $(\mathrm{Mc} 7,34)$ il Cristo restituisce la parola al sordomuto, gli dissigilla le labbra e l'udito. Nel vangelo il miracolo avviene, qui no: le palme non sono più palme; la lettura del mondo è impossibile, non c'è corrispondenza tra le capacità intellettive e il sistema di segni, il contesto è indecifrabile. Come per un improvviso black-out il poeta diventa cieco, sordo e muto, e non può spezzare il sigillo che chiude la realtà, precludendola alla sua conoscenza. Il poeta sta cercando il suo essere nel mondo e il mondo non glielo consegna.

Eppure il tentativo di immedesimazione e assunzione profonda della natura, seppure qui fallimentare, costituisce una nuova direzionalità che conduce ad una reale possibilità di ottenere la rivelazione cercata. A questo punto, scrive Crespo:

di fronte a questa incapacità di vedere e di udire non ci può essere altro che una distruzione o una ascesi. Distruzione non c'è dato che la poesia continua e, effettivamente, c'è un tentativo di ascesi che si riferisce allo spirito del poeta ${ }^{51}$.

La personale ascesi del poeta "comincia con l'identificazione con la sua propria parola poetica ${ }^{52 "}$, e si sviluppa nella direzione di una mimesi della realtà e di una speculazione spirituale.

Mímesis no significa, en este caso ni creo que pueda significarlo nunca remedo exterior de la realidad, sino inmersión en esa misma realidad, identificación profunda con ella, hasta el extremo de que, una vez descubierta sea imposible regresar al punto de partida, encontrar de nuevo la orilla de la realidad aparente. [...] pues ¿quién es capaz de renegar de una experiencia iluminadora, si la ha vivido con verdad y entrega? ${ }^{23}$

\footnotetext{
51 Autolettura a Parma, cit., p. 43.

52 Ibidem.

53 Ángel Crespo, Presentación de El bosque trasparente, cit.
} 
Inmersión, identificación profunda ed entrega sono effettivamente le modalità con cui il poeta entra in una relazione totalizzante, fisica e spirituale con la realtà, nella speranza che essa ricambi, consegnando al poeta il suo mistero. Eternidad segunda ${ }^{54}$

Metí las manos en el agua

para parecerme a las islas.

Por mis dedos pasaba el mar como el aire por las rendijas.
Por debajo de mis palabras

las sirenas se perseguían.

cuando quise volver a la tierra

ya no estaba la orilla.

Il gesto sacrale dell'immersione delle mani nell'elemento acquatico, sta qui proprio a rappresentare la mimesi come immedesimazione fisica del poeta con il mondo. La penetrazione dell'acqua ha l'esplicito scopo di assimilarsi ("para parecerme") agli elementi del paesaggio marino, mentre l'elemento primordiale ed archetipico ("el mar") si costituisce flusso ("por mis dedos pasaba") assoluto dell'elemento vitale (nella sua metamorfosi poetica in aria: "como el aire"), come da memoria eracliteana, esperienza cosmica dello scorrere del Tutto. L'esperienza in limine di assoluto, proprio en la orilla dell'assoluto, è una dedicazione totale che rende impossibile qualsiasi ritorno: la riva che scompare nega per sempre al poeta iniziato il ritorno alla stabilità delle certezze terrene, soprattutto perché egli oltre alle mani, ha immerso nella corrente cosmica le proprie parole, cui il cosmo ha dato la sua risposta di armonia nella danza delle Sirene ("por debajo de mis palabras / las sirenas se perseguían").

Del resto la parola poetica risulta essere una faccia inseparabile della medaglia che è l'identità del poeta: il conio più antico e il più profondo. Por el metal profundo 55

¿Quién sería capaz de separar las dos caras de una moneda? [...]Una es, no media y media. Si cae en el río, sus dos caras se ahogan en el limo o desembocan en el mar. [...] Y, contemplada por uno de ellos, sabemos que está entera porque, sin verlo, estamos adivinando, sintiendo tocando casi siempre - al que no cupo en suerte. [...] ¿Quién sería capaz de apartarnos a ti y a mi palabra mía? Unidos por lo no visible, por el metal profundo, repetimos - inauguramos la más antigua de las acuñaciones. Somos - si somos - la moneda que no se gasta, que no se

\footnotetext{
${ }^{54} \mathrm{Da}$ El bosque transparente, in Poesía 1996, tomo 2, p. 43.

${ }^{55} \mathrm{Da}$ El bosque transparente, in Poesía 1996, tomo 2, p. 139.
} 
parte, pero se reparte. De una cara a la otra, el amor mide sus tamaños. Y siempre crece. Moneda viva, infinita: nada se niega a sus cifras proteicas. Moneda, no obstante que nada compra: porque todo - todo lo que existe o pueda existir - es absolutamente suyo.

Identico destino condiviso, quello del poeta e della parola, in bilico tra la perenne alternativa dell'affogare nel fango o lo sfociare nel mare, tra l'opacità soffocante del fango e l'infinita potenzialità creatrice di un mare divinizzato dalla presenza di Proteo ("cifras protéicas") e quindi luogo dell'oracolo. L'unità inscindibile delle due facce della moneta è anche cifra della stessa realtà del mondo, che nell'apparenza visibile di una sola delle due facce, lascia intuire quella nascosta ("sin verlo, estamos adivinando, sintiendo - tocando casi siempre - al [lado] que no cupo en suerte").

Il passaggio dalla cecità alla luce, costituisce una lenta e faticosa ascesi personale e poetica, in cui un'instancabile ricerca assedia le realtà mondane e spirituali in continui tentativi di espressione.

Tale passaggio implica un processo di metamorfosi, una sorta di "alchimia spirituale ${ }^{56 "}$ come fusione e trasformazione, che si svolge sotto il patronato del dio Hermes, il dio delle trasformazioni e della coincidentia oppositorum, inventore della parola (e non a caso "patrono" dell'arte traduttoria, la herméneutikè teknè), simboleggiato nel fuoco, l'ignis mercurialis (il fuoco è proprio il principale agente di metamorfosi nella poesia di Crespo, mentre, nell'alchimia, il mercurio costituisce l'agente di trasformazione dei metalli in oro) come luce rivelatrice e mistica sorgente di conoscenza. Scrive a questo proposito Pilar Gómez Bedate ${ }^{57}$ :

la posibilidad de la metamorfosis personal y el trabajo en su cumplimiento, es el significado que podríamos llamar más literal de la poesía de esta época [gli anni settanta, che concidono con il lavoro di traduzione della Commedia] y es abordado desde múltiples perspectivas aunque siempre con un sentido moral que identifica el conocimiento con la perfección de la personalidad.

\footnotetext{
${ }^{56}$ Con questa espressione Crespo descrive il clima del Purgatorio dantesco nella sua introduzione a Divina Commedia, Planeta, Barcelona 1999, p. XXVII.

${ }^{57}$ Pilar Gómez Bedate, Una aproximación a los dioses de Ángel Crespo, cit., p. 123.
} 
La poesia crespiana si arricchisce di profonde suggestioni simboliche alchemico-ermetiche. Il fuoco diventa elemento privilegiato, in quanto elemento di luce, elemento metamorfico e principale agente di metamorfosi.

Con un surplus di luce inizia la condizione in cui il poeta può riconoscere la sua propria forma: Luz en Lucerna ${ }^{58}$ l'allitterazione della luce (luz - Lucerna) inaugura il recupero della vista interiore.

\footnotetext{
Si fuese de la tierra, me podría

pensar eterno: al menos como

la cresta azul de la montaña

inaccesible a las gaviotas

que llegan de otro origen.

Pero yo no soy de la forma

que se complace en sí misma hijo,

y son mis alimentos
}

\author{
el aire que, más alto la avasalla \\ y el agua que por dentro y por fuera \\ la va reduciendo a llanura \\ sobre la que han de correr \\ todas las tribus del deseo, \\ y el fuego que es el único \\ vencedor. Pues a todos \\ nos sabe consumir. \\ En él me sé más cerca de mi ser.
}

Aria, acqua e fuoco, elementi dinamici, metamorfici, inafferrabili e meno definibili, sono quelli che formano e alimentano l'essere del poeta. Cui pure l'elemento terra darebbe una illusione di eternità ("si fuese... me podría"), ma, in quanto preclude ogni possibilità di metamorfosi, la forma statica "que se complace en sí misma", che cioè trova soddisfazione nella sua staticità illusoria di forma, si allontana dalla verità dell'essere del poeta. Si noti il forte iperbato ("Pero yo no soy de la forma / que se complace en si misma hijo"), tratto stilistico di cui Crespo fa molto uso nella traduzione della Commedia, che pare proprio spezzare dall'interno la forma in cui il poeta non si riconosce. La forma definita si rivela illusoria in quanto assoggettata e modellata, a sua insaputa dal dominio dell'aria, dal lavorio dell'acqua e dal potere consumatore del fuoco. E proprio con la potenzialità di consunzione del fuoco, suprema ed unica metamorfosi capace di rivelare la verità e la divinità delle

\footnotetext{
${ }^{58}$ Da El bosque transparente, in Poesía 1996, tomo 2, p. 91.
} 
$\operatorname{cose}^{59}$, si identifica l'essere del poeta; luce e consumazione teofaniche, dignificazione ultima di tutto ciò che esiste, fuoco come "único vencedor" proprio in forza di questa sua capacità di luce e metamorfosi che lo rende gemello allo spirito di una poesia, come quella crespiana che tende instancabilmente alla parola teofanica imbevuta di luce.

Fuoco come possibilità di trascendimento integrale, che consegnerebbe alla poesia il reale redento dalla sua opacità ed inconsistenza. Fuoco come ardore conoscitivo e potenza vittoriosa sulle tenebre dell'ignoranza e del non essere, che rappresenta la più profonda essenza della missione del poeta, secondo il celebre aforisma juanramoniano: "todo verdadero poeta lo es de transición. Su función es la de recojer la llama quemándose, quemarse él y pasarla quemando".

Ad una anteriorità di ignoranza si oppone ora la faticosa - e sempre parziale, in quanto sempre procurata con le proprie uniche forze, mai ricevuta per grazia luce di una nuova visibilità, trasparenza dello sguardo interiore e rivelazione della perspicuitas delle cose, contro la loro esibita e costante inespressività. Così in El pabilo $^{60}$, lo stoppino simbolico di una luce precaria, che pure enormemente si oppone alla "paciencia triste" delle cose, come una loro attesa rassegnata di una volontà che possa trarle dall'oscurità alla luce del significato. Lo stoppino possiede però l'ambiguità semantica della miccia, come possibilità di deflagrazione della luce.

\footnotetext{
59 "Sólo el fuego desvela la belleza / secreta de las cosas, / les desnuda el espíritu. / [...] el estiércol / tejido / es, al arder, digno de un dios [...] Todo, al arder, se iguala". Celebración del fuego, in Poesía 1996, tomo 3, p. 169.

${ }^{60}$ Da El bosque transparente, in Poesía 1996, tomo 2, p. 168.
} 


\begin{tabular}{ll}
\multicolumn{1}{c}{ Enciendo la vela para } & el aire es ya continente \\
verme, para contemplar & sin muertes en sus entrañas, \\
lo que me rodea: es & la tierra recobra altura \\
como un mar que va cediendo & - translúcida, huracanada - \\
extensión y fondo, como & y, cuando todo comienza \\
un aire que quiere abrirme & a ser luz (no la que yo \\
sus caminos más ocultos; & he prendido, sino lumbre \\
lo mismo que un bosque de & que las miradas enciende), \\
ramas y hojas transparentes. & apago el pabilo, y todo \\
Lo distinto cede, el mar & vuelve a su paciencia triste: \\
se puebla de árboles y aves & no pude seguir mirando \\
& al interior de la llama
\end{tabular}

Il gesto fortemente sottolineato in incipit del primo verso "enciendo", riferisce tutta l'intensità volontaristica del creatore di luce: il poeta aggetta come soggetto attivo dell'atto luciferino, di cui si esprime chiaramente la finalità ("para" ripetuto due volte) conoscitiva nelle due direzioni dello sguardo interiore ("para verme") e della contemplazione delle cose ("para contemplar lo que me rodea"). Ciò che si produce all'accensione del lucignolo, è, effettivamente, una deflagrazione luminosa, che investe, attraverso il fuoco della candela, l'elemento acquatico ("un mar") e l'elemento aereo ("un aire"), tanto da ottenere la trasparenza del bosco. La deflagrazione della visione, pare produrre una sorta di onda d'urto di fronte alla quale si ritirano le acque del mare ("un mar que va cediendo extensión") e le facili apparenze ("lo distinto cede", cioè ciò che è chiaramente ed immediatamente visibile) e cambia l'aspetto consueto del mondo ("el mar se puebla de árboles y aves", alla vita marina si sostituisce una vita terrestre, l'acqua si fa elemento respirabile e simbolicamente si creano le condizioni per la sussistenza del canto) affrancato dal limite della morte ("sin muertes en sus entrañas"). Si tratta quindi di una condizione edenica. La terra stessa è imbevuta di luce ("translúcida61"),

\footnotetext{
${ }^{61}$ Se l'aggettivo "lúcido", indica di per sé uno stato di luminosità e trasparenza, l'aggiunta del prefisso trans- comporta proprio il passaggio della luce, quindi uno stato straordinario dell'elemento terra che si fa permeabile alla luce.
} 
luminosità sconvolta ("huracanada"), in quanto la perspicuitas sovverte l'ordine apparente delle cose. La deflagrazione della luce provoca una totalità di luce (“todo comienza / a ser luz") che si attesta su un principio di rivelazione ("comienza a ser") e che trascende il gesto iniziale del poeta (che qui si riafferma come soggetto, sbalzando il pronome personale in chiusura di verso): "no la que yo / he prendido sino lumbre / que las miradas enciende", e dichiara finalmente la sua qualità di luce intellettuale, lume di conoscenza capace di accendere gli sguardi; da cui si intuisce la missione corale della poesia come atto di rivelazione. La sacralità di tale rivelazione è denunciata dall'impossibilità degli occhi di persistere nella visione: "no pude seguir mirando", occorre "apagar el pabilo" per non incorrere, come Semélè, nell'autodistruzione.

L'affinamento della visione, come faticosa edificazione interiore, coltura totalizzante di potenzialità esistenti in nuce che devono esplicarsi in un lento cammino verso la perfezione, inaugura l'aprirsi di prospettive inedite nel mondo prima muto "cuando el poeta logra levantar el penúltimo velo, más tupido que los anteriores y menos que el siguiente ${ }^{62 "}$. La natura appare finalmente come possibilità di manifestazione, di teofania dello spirito in El Pedregal63:

\footnotetext{
¿Son alas deshojadas, huesos, tristes

o una muralla, por la que pasean

restos de algún naufragio,

centinelas y brumas,

trances sin nombre,

y el mediodía se alzará lo mismo

tiempo derrumbado

que una rama que crece.

- o no son más que piedras?

O tal vez no.

Detrás de ellas habrá un paisaje abierto

Me paro junto a este

o soledad tan sólo;

pedregal: no me atrevo

habrá un vuelo, un tumulto acre de plumas,

a dar un paso más

un fragor de olas contra el casco vivo,

hacia lo que me engaña revelándose.

62 Á. C., Entre el temor y la esperanza, Notas acerca de mi poesía, in AA. DD. Ángel Crespo, una obra completa, "Quimera" Revista de Literatura, n. 254, Barcelona, marzo 2005, p. 11.

${ }^{63} \mathrm{Da}$ El bosque transparente, in Poesía 1996, tomo 2, p. 178.
} 
In questo testo è proprio la pietra, concrezione materica pura, inerzia dell'elemento terrestre, a farsi varco su possibilità appena accennate e ancora ambigue di rivelazione ("lo que me engaña revelándose"). I quesiti lanciati contro l'insieme disorganizzato di pietre ("¿... o no son más que piedras?”, "Detrás de ellas habrá un paisaje abierto / o soledad tan sólo"), denotano, nei giri avverbiali attorno a cui si svolgono, l'accendersi della visione di fughe prospettiche di universi alternativi al caos inespressivo dell'apparente con cui la realtà si presenta al primo impatto. Come dinanzi alla sacralità di una iconostasi, il poeta neofita della visione si arresta, "me paro [...] no me atrevo a dar un paso más", preda di un'iniziale paralisi reverenziale innanzi alla possibilità di una rivelazione che trascenderebbe il suo stesso essere e la sua stessa ansia gnoseologica.

Quel "paso más" viene osato ${ }^{64}$, secondo quanto afferma lo stesso Crespo, al aire de los dioses 65 , cioè nello spazio di assoluta trasparenza dell'elemento aereo, alla presenza numinosa e luminosa di quel sacro latente nella realtà fenomenica, ed in essa sempre ricercato in un costante assedio che giunge ora ad offrire i suoi primi frutti. La rivelazione teofanica non avviene mai "per grazia ricevuta", ma nella faticosa opera del poeta la cui attività creatrice si attesta fortemente nella direzione di una fede non rivelata, ma totalizzante nella numinosità occulta dietro ogni aspetto dell'essere. La fede nel divino è condizione necessaria al fare poetico66:

\footnotetext{
${ }^{64}$ Cfr. Autolettura a Parma, cit., p.46, dove, proprio dopo il commento della poesia El Pedregal, il poeta afferma: "il passaggio seguente, che infine oso fare nel libro ora in corso di stampa El aire es de los dioses $[\ldots]^{\prime \prime}$.

${ }^{65} \mathrm{Al}$ aire de los dioses, evidente citazione sanjuaniana con echi guilleniani, è il sottotitolo della prima parte della raccolta poetica El aire es de los dioses (1978-1981), che significativamente conclude El bosque transparente.

${ }^{66}$ Sólo quien cree en los dioses, in El aire es de los dioses (1978-1981), dalla raccolta El bosque transparente, cit. p. 159. (Esclusa dalla poesia completa del 1996).
} 
Sólo quien cree en los dioses,

en sus pechos

ni benignos ni aciagos,

en sus ojos

que todo lo someten,

puede decirse hermano suyo y espejo ser de un dios.

Él colaborará en la creación

de otros mundos:

irá

a colocar la luz contra la piedra

en un paisaje ciego [...]

Il fattore primario della numinosità, non è qui il suo essere in rapporto all'uomo, il suo rivolgere al mondo uno sguardo benigno o infausto (" $\mathrm{ni}$ benignos ni aciagos"67), ma il fatto di essere un assoluto totalizzante ("todo lo someten") che si diffonde in tutte le realtà. Se ogni manifestazione dell'essere è manifestazione divina, la creazione poetica deve necessariamente essere specchio di quella numinosità ("hermano suyo", "espejo ser de un dios"). Solo così, si compie la condizione per cui il poeta può veramente coincidere con il suo essere poietés 68 , e collaborare alla creazione. E la collaborazione creativa del poeta consiste nel dare significato alle cose, proprio aprire il "paisaje ciego" a prospettive di inedite visioni ("otros mundos"). "Colocar la luz contra la piedra", luce e pietra sono gli estremi della visione. Dove la pietra è la muta materia, seppure in tutta la sua inespressa potenzialità teofanica, la luce è invece la dichiarata messa a frutto del germe di vita razionale che costituisce la fondamentale alternativa nella realizzazione dell'essere in potenza delle cose.

L'assoluta trasparenza dell'aria, come elemento proprio del nume, si rende palpabile nell'acqua piovana, aqua vitae che discende dal cielo ad impregnare la terra della sua fecondità divinizzante. Il momento teofanico è esattamente determinato ("esta lluvia") ed è afferrabile solo dal poeta ("os palpé [yo]", "mis manos", "mis

\footnotetext{
${ }^{67}$ Questo concetto del divino è strettamente rapportabile al concetto classico delle divinità grecolatine, che non intervengono nelle cose della terra, racchiuse in uno stato di beatitudine celeste alla quale non rinunciano per coinvolgersi con la vita dell'uomo.

${ }^{68}$ Il verbo greco poiéin possiede notoriamente l'accezione di creare, dare vita.
} 
dedos") come soggetto privilegiato di una manifestazione individuale. En esta lluvia69:

$$
\text { Os palpé en esta lluvia }
$$

no en el aire,

sino en la tierra, tras haber caído

- entre la hierba fría

y caliente, como una boca

grande y verde que no devora tiempos:

mis manos ahora huelen

a aceite de podrido

y lujuriante azahar (mis dedos ya planetas del árbol)

y también a una axila rosa

$\mathrm{y}$ al escozor de un vientre no virgen, tras la lluvia.

Estabais allí tras el agua

- o sea allí en la lluvia -

como jugando a ser espejos

más que su fibra ambigua,

pero era vuestro el aire.

La rivelazione è qui innanzitutto sensoriale, palpabile dalle mani e dita del poeta, concretamente colta in una terra feconda, "entre la hierba", capace di essere alimento come pascolo erboso, e viva nei suoi contrasti ("fría y caliente"). Le mani del poeta, che si fanno qui forma del contatto con la terra sacralizzata dalla pioggia divina per appropriarsene (nei diarî si trova questa affermazione apparentemente casuale: “¿Mis sentidos? creo que el más agudo es el tacto $\left.{ }^{70 ”}\right)$, ricevono da quel contatto una sorta di unzione sacramentale ("mis mano ahora huelen a aceite") con l'olio del fior di zagara ("podrido y lujuriante azahar") nella sua lussureggiante putrescenza, come intensità di profumo che ha potere lenitivo, e purezza simbolica di una catarsi avvenuta tramite il contatto con l'acqua divina. Attraverso la cortina di pioggia ("tras la lluvia”, "tras el agua") il baluginare ambiguo del corpo della dea ("una axila rosa", "un vientre"). Il contatto sensuale con questo corpo segnano profondamente le mani e le dita del poeta, che ne conservano la traccia come una bruciatura (il termine "escozor"1" rivela l'intervento del fuoco che completa la presenza dei quattro elementi) azzardato contatto con qualcosa di "vedado a los

\footnotetext{
${ }^{69} \mathrm{Da}$ El bosque transparente, in Poesía 1996, tomo 2, p. 224.

70 Á.C. Los trabajos del espíritu, cit., p.358.

71 Il termine escozor è sostantivo derivato dal verbo escocer dal latino EXCOQUĚRE che indica "el hacerse sentir una parte del cuerpo con la sensación que produce una quemadura, el contacto de una cosa como un ácido en una herida". Cfr. Moliner, s.v. escozor.
} 
mortales ${ }^{72 "}$. La persistenza indelebile ("ahora huelen") dell'odore e del fuoco sacro ("escozor") rimane come testimonianza certa dell'ambigua visione ("estábais allí") mai definitiva.

Nell'universo poetico crespiano, l'unico contraltare all'eternità del dubbio, non è mai lo splendore definitivo ed assoluto della suprema rivelazione del Paradiso dantesco. La visione crespiana, più esattamente una divinazione, non trascende mai i confini del mondo e non si situa mai nell'Empireo, ma rimane nella göttlichgegenwärtige Natur, una natura che rende attuale la presenza della numinosità che essa stessa racchiude. La poesia significativamente titolata $\mathrm{Al}$ dios desconocido ${ }^{73}$, al dio ignoto si pone nella tradizione grecolatina per cui si costruiva un altare anche per le divinità di cui non si sapeva il nome, per essere sicuri che ogni aspetto del dio fosse comunque onorato. Negli ultimi due testi, che prendo in considerazione, mi pare interessante sottolineare il passaggio al tratamiento de tú che il poeta riserva ora al dio in un dialogo che si mostra infatti sempre più personale e clarividente.

\footnotetext{
Reluces en la piel

de los toros, en los tobillos

de la doncella, en las

ondas vagas del agua

del arroyo del prado,

en la ceniza, en las paredes

encaladas.
}

\author{
¿Qué dios eres? ¿O acaso \\ eres diosa? ¿O no eres? \\ Quiero ver \\ tus ojos hondos o tus senos \\ altos, pero me impiden \\ sorprenderte mis ojos, \\ en los que más reluces.
}

Reluces en la oscuridad.

Al lato della triplice domanda, espressione del dubbio inesauribile, si pone il relucir del dio, lucore pleonastico in se stesso, in quanto non si tratta di un semplice splendore ma di un raddoppiato ri-splendere, tre volte ribadito, e la forte espressione della volontà di vedere del soggetto ("quiero ver" espressione isolata ad occupare un intero verso trisillabo, e nel contesto della tendenza crespiana alla numerologia simbolica ed al ritmo simbolico del verso, il tre ricorre simbolicamente in questo testo

\footnotetext{
72 Orillas del Meno, da El bosque transparente, in Poesía 1996, tomo 2, p. 88.

${ }^{73}$ Da El bosque transparente, in Poesía 1996, tomo 2, p. 218.
} 
come numero della divinità), a cui si oppone l'ostacolo paradossale degli stessi occhi del poeta come sede del maggiore splendore della divinità che acceca il poeta stesso.

Al culmine della visione dantesca si pongono le parole immortali della preghiera alla Vergine di San Bernardo, che implora per il poeta il disvelarsi de "l'ultima salute".

Seppure non si può parlare di culmine in un percorso che non concepisce rivelazioni, ma solo una inesausta ed inesauribile ricerca, a questo punto del percorso artistico ed esistenziale di Ángel Crespo, la voce intima del poeta si leva sobriamente in una personale parola rivolta al dio, in una totale entrega, nella preghiera che il dio stesso si appropri profondamente della sua parola ${ }^{74}$.

\footnotetext{
Del mundo que yo ignoro tú procedes ardiente de belleza que yo ilumino porque sé que existe tanta hermosura. Vienes tú, de frente tú como cae la hoja del árbol y hasta mí la empuja el viento;
}

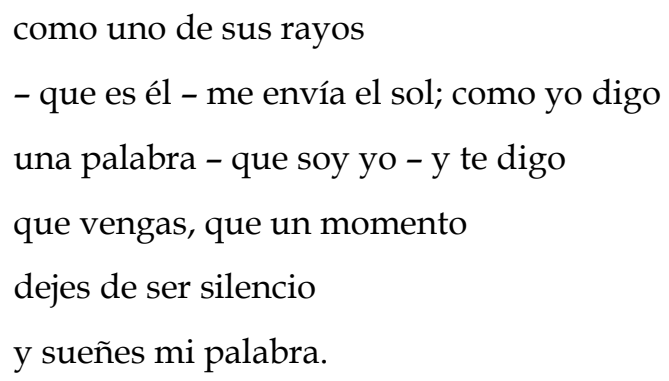

Il $t u$, ancora ignoto ("del mundo que yo ignoro"), ma ormai certamente saputo ("sé que existe"), si fa qui messaggio ardente di una bellezza che è l'oggetto della costante ricerca poetica. Attività poetica come processo di illuminazione ("yo ilumino") operato in prima persona dal poeta ("yo"), per cui la lunga ricerca del cammino alla perfezione porta all'esperita certezza dell'esistenza del mondo della divinità di luce e bellezza. Risultato dell'inesausto struggle poetico per conquistare il significato delle cose è l'avvento ("vienes") "de frente" del dio, ancora parziale annuncio del mondo da cui proviene, come una foglia è parte all'albero, eppure parte che ne è essenza compartecipe, come il raggio è parte del sole ed insieme il sole stesso ("como cae la hoja / del árbol y hasta mí la empuja el viento; / como uno de sus rayos / - que es él - me envía el sol"). La dinamica della entrega tra poeta e divinità è reciproca, al movimento del dio verso il poeta, che il poeta ha meritato con

\footnotetext{
${ }^{74}$ El dios soñado, in El aire es de los dioses (1978-1981), dalla raccolta El bosque transparente, cit. p.167.
} 
la sua opera, si oppone il movimento del poeta della consegna di sé al dio: il poeta consegna se stesso sub specie di parola, della sua voce, suo decisivo segnale di identità. E chiede al dio che nella sua dimensione di silenzio, trascendimento in purezza della parola, sia accolta profondamente la parola poetica, che la parola del poeta possa essere ricreata nel sogno del dio dormiente.

\section{BIBLIOGRAFÍA}

Balcells, J. M. (1990): Poesía y poética de Ángel Crespo, Prensa Universitaria, Palma de Mallorca.

Bertelloni, M. (1996): El mundo poético de Ángel Crespo, Huerga y Fierro, Madrid.

Crespo, Á. (1983): El bosque transparente (Poesía 1971-1981), Ed. Seix Barral, Barcelona.

Crespo, Á. (1971): En medio del camino (Poesía 1949-1970), Ed. Seix Barral, Barcelona.

Crespo, Á. (1996): Poesía, ed. de Pilar Gómez Bedate y Antonio Piedra, Fundación Jorge Guillén, Valladolid.

Crespo, Á. (1999): Dante y su obra, El Acantilado, Barcelona.

AA. DD. (1999): Ángel Crespo: una poética iluminante, Biblioteca de Autores Manchegos, Ciudad Real.

AA. DD. (2000): En Florencia, para Ángel Crespo y su poesía. Atti della Giornata di Studî, Dipartimento di Lingue e Letterature Neolatine, Firenze, 7 dicembre 1999, Alinea, Firenze.

AA. DD. (1989): El tiempo en la palabra, numero monografico su Ángel Crespo di "Anthropos", Revista de Documentación Científica de la Cultura, e “Anthropos", Suplementos n. 15, giugno 1989. 